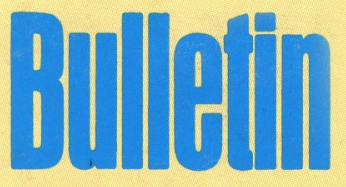

\title{
of the Ameriball
}

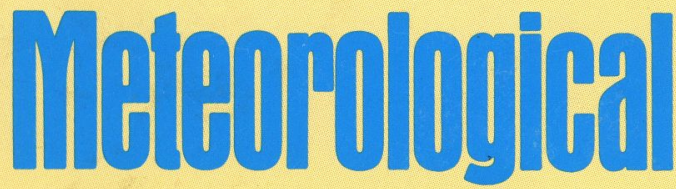

SOcifll

\section{WCRP/ISCCP INFRARED RADIANCE ANALYSIS}


UATER 

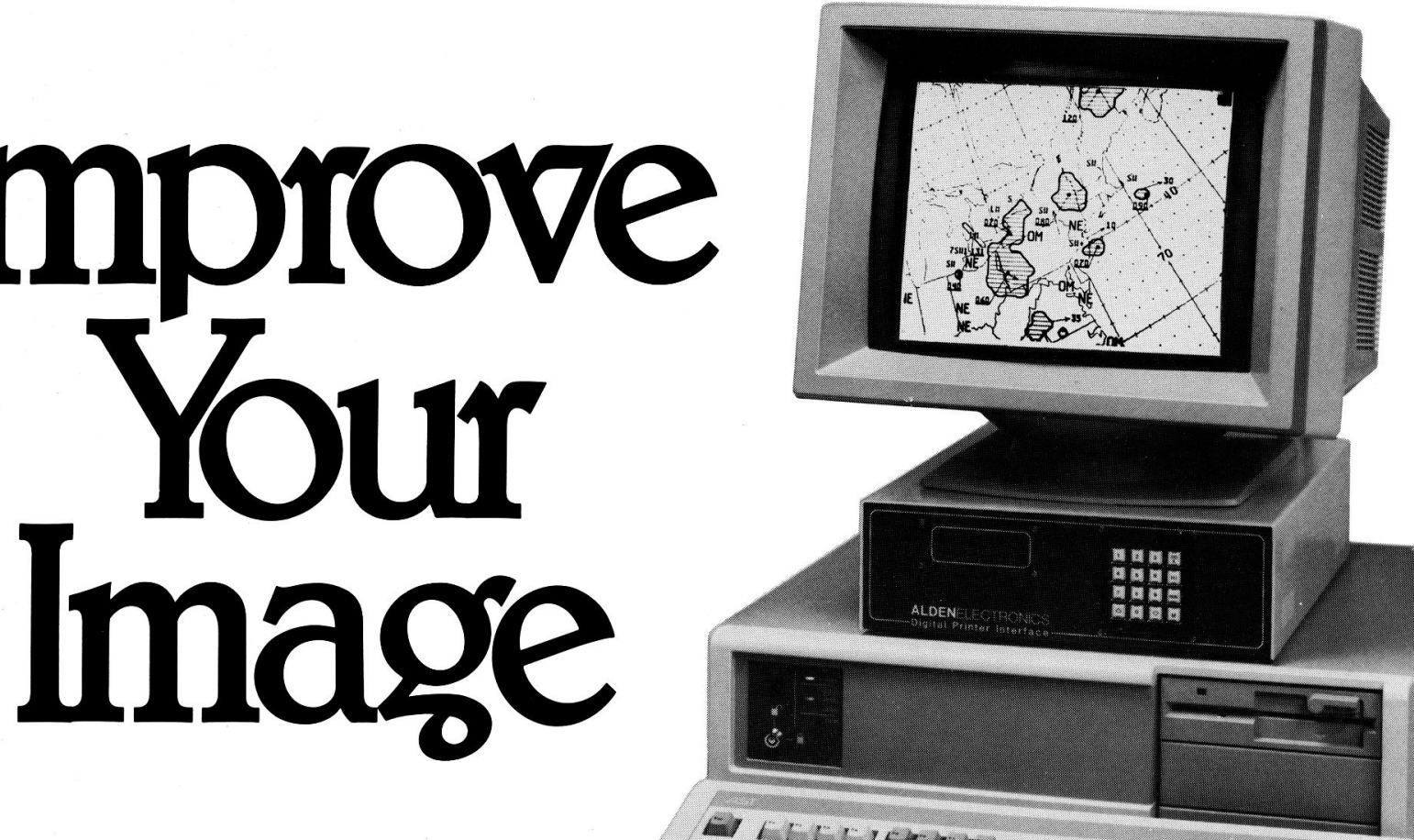

\section{When you want a clearer}

picture of the weather in your

region, zoom in on Alden's new D100 DIFAX display system.

The D100 is a PC-based work station that lets you select any of the DIFAX charts available, automatically store them in memory, and call them up on a monitor.

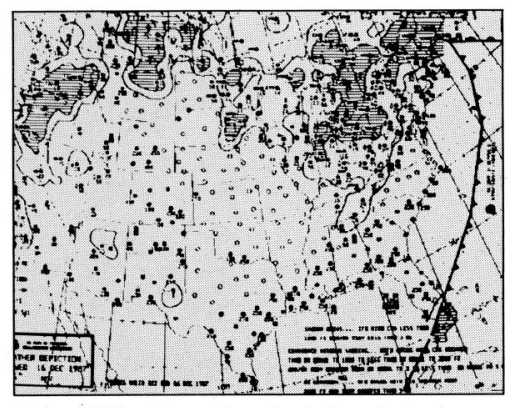

The full-frame weather depiction chart gives an overall view of the country's weather.

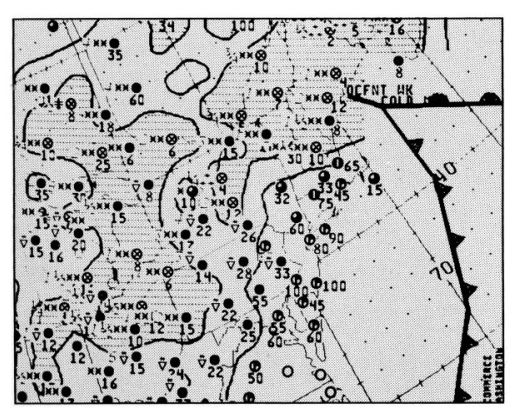

Zooming in, you get a high-resolution display of your own region that's easier to work with.
Best of all, the D100 lets you store portions of these charts for detailed analysis of your own region. You zoom in on the exact area you need. The area selected is displayed at a much higher resolution rate for dramatically improved readability.

Another unique feature is looping. For example, you can store sequential radar summaries, then loop through them-either automatically or manually-for a view of the progression of the weather.

Hard copies of any charts are available on Alden's dot matrix printer through an easy-to-use automatic or manual selection process.

For more information on the D100, call or write Alden Electronics, 47A Washington Street, Westborough, MA 01581. (508) 366-8851

\section{ALDENELECTRONICS}




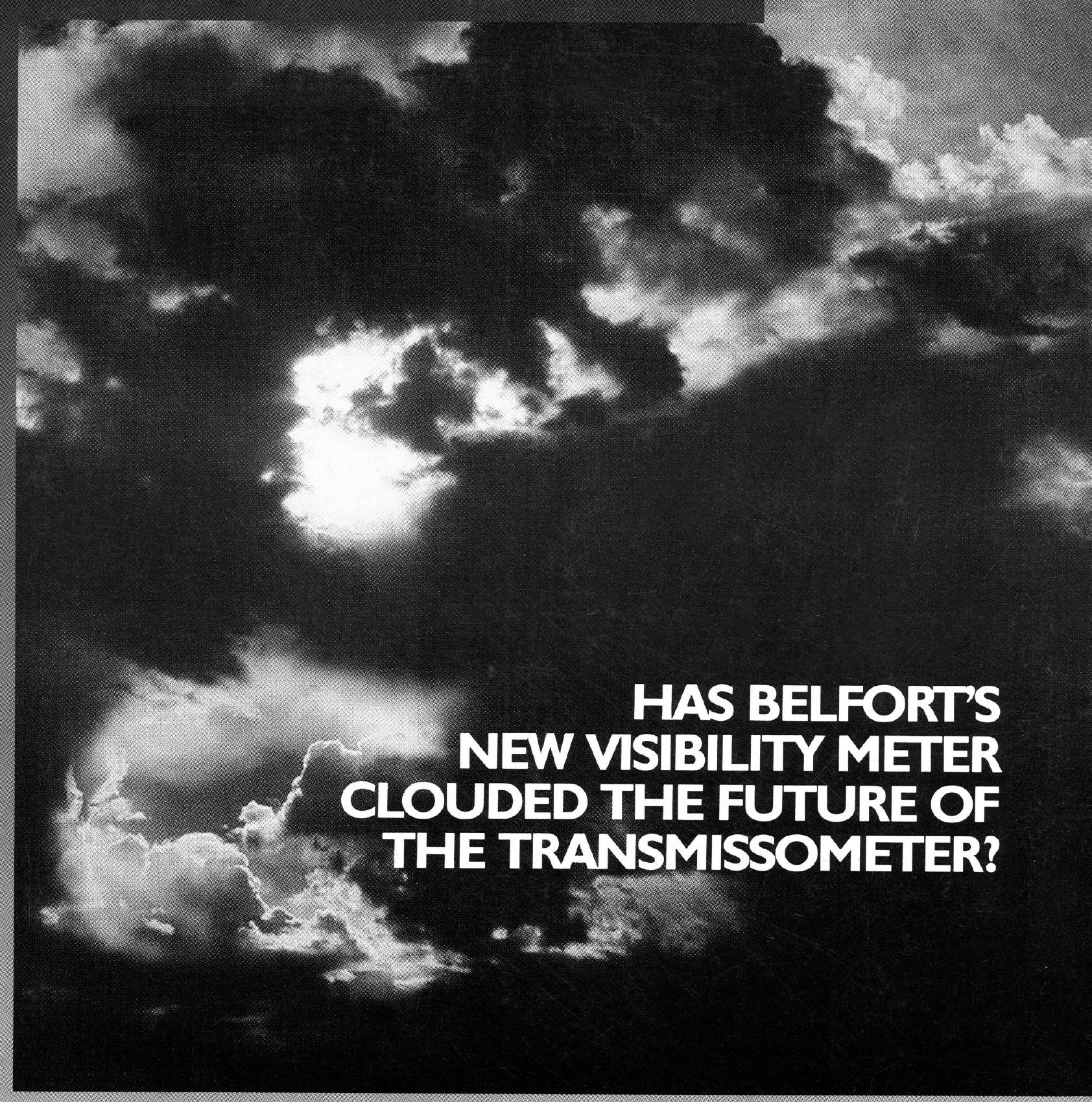

Perno

souve heard or read about it

Belfort's powertul new forward-scatter visibility meter. It outperforms the transmissometer in a number of key areas.

Take accuracy.

The transmissometer provides superior accuracy under optimum laboratory conditions. But the visibility meter does far better in the field, determining atmospheric visibility over an incredible range of 50 feet to 30 miles, in all weather conditions, with better accuracy.

While the transmissometer requires maintenance on a monthly basis, the visibility meter only needs it twice a year. And, unlike the transmissometer, it can be calibrated quickly and easily in any kind of weather-even rain.

The compact single-pole visibility meter is also much easier to install. And it costs substantially less, while saving even more money on maintenance and calibration.

Does this mean the beginning of the end of the transmissometer? Help decide for yourself. Call or write for more information. Belfort Instrument, 727 S. Wolfe Street, Baltimore, MD 21231 301-342-2626 FAX:301-342-7028 87528 BELFORT-BAL

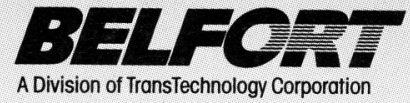

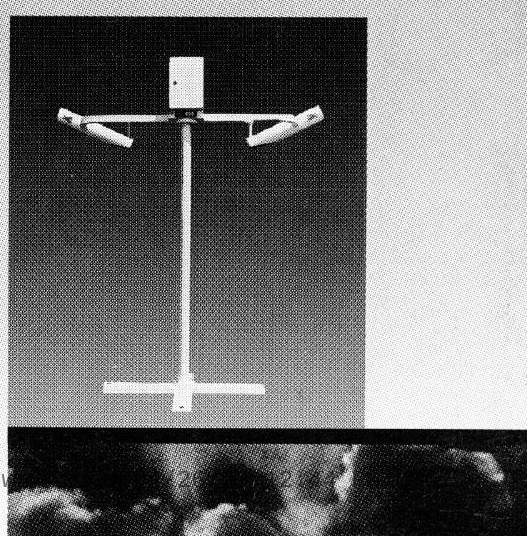




\section{Bulletin of the American Meteorological Society}

Editor, Richard E. Hallgren

Publications Manager, Arlyn S. Powell

Technical Editor, Irwin B. Abrams

Educational Affairs Editor,

David D. Houghton

News Editor, Brenda M. Gray

Production Editor, John Forgetta

Meetings Editor, Evelyn Mazur

Editorial Assistant, Tracey Pepper

Advertising, Mary L. McMahon

The Bulletin of the American Meteorological Society is the official organ of the Society, devoted to editorial, survey articles, professional and membership news, announcements, and Society activities. Editing and publishing are under the direction of Richard E. Hallgren, Executive Director. Members are encouraged to send information to be considered for publication. Send four copies of each manuscript (text and illustrations). For guidance on preparation and style, see "Information for Contributors" on inside covers of a recent AMS research journal.

AMS Officers, Councilors, and Commissioners: President, William D. Bonner; President-Elect, Donald R Johnson; Past President, James R. Mahoney; Councilors, Ron L. Alberty, Kirk Bryan, Jr., Stanley A Changnon, William M. Frank, Neil L. Frank, Robert J. Gurney, Kristina B. Katsaros, Robert A. Maddox, Jerry D. Mahlmann, Ronald D. McPherson, Roddy R. Rogers, James R. Scoggins, Robert J. Serafin, Caol L. Weaver: Commissioners, David D. Houghton, Clifford J. Murino, Harold D. Orville, Richard E. Orville, and Robert T. Ryan.

The Bulletin of the American Meteorological Society (ISSN 0003-0007) is published monthly by the Amercan Meteorological Society, 45 Beacon St., Boston, MA 02108 . Second-class postage paid at Boston, MA and at additional mailing offices. Subscription price to members is included in annual dues ( $\$ 30$ per year) Subscription price to nonmembers is available on request; single issues are $\$ 15$ each. Address all busines communications, purchase orders, and inquiries to the Executive Director American Meteorological Society, 45 Beacon St., Boston, MA 02108 (617-227-2425). POSTMASTER: Send address changes to Bulletin of the American Meteorological Society, 45 Beacon St. Boston, MA 02108.

\section{articles}

ISCCP Cloud Data Products.

William B. Rossow and Robert A. Schiffer

The Potential Impacts of Climate Change on the Great Lakes

Joel B. Smith

The Transition from the Present Radar Dissemination System to the NEXRAD Information Dissemination Service (NIDS)

Vico E. Baer

Global Change, A Catalyst for the Development of Hydrolic Science

Peter S. Eagleson

Andrew F. Bunker: Pioneering in Air-Sea Interaction Research 1946-79

Carl A. Friehe and Henry M. Stommel

meeting review

Upper-Air Measurements and Instrumentation Workshop

Frederick G. Finger and Francis J. Schmidlin

\section{special news features}

Policy Statement of the American Meteorological Society on Global

Climate Change. 57

What is a Meteorologist? calendar....................................... 92

corporation members....................111

AMS conference schedules......... 113

professional directory.................. 144

25 years ago.................................. 158

50 years ago................................. 158

index to advertisers...................... 158

Cover: Brightness temperature image of the earth on 4 July 1983 at 1500 UTC, as viewed by a hypothetical geostationary satellite at $25^{\circ} \mathrm{W}$, synthesized from data taken by METEOSAT-2. GOES-5, and NOAA-7 for ISCCP. Application of different color tables representing the brightness temperatures of clear scenes over land, open water, or snow/ice and cloudy scenes depends on the ISCCP cloud detection analysis. Spatial resolution is approximately $55 \mathrm{~km}$.

(1) Copyright 1991, American Meteorological Society (AMS). Permission to use figures, tables, and brief excerpts from this journal in scientific and educational work is hereby granted, provided source is acknowledged. Any use of the material in this journal is considered to be "fair use" under Section 107 or that satisfies the conditions specified in Section 108 of the U.S. Copyright Law (17 USC, as revised by P.L. 94-553) does not require the Society's permission. Items that do not bear their own separate copyright notices either are in the public domain or are U.S. Government works for which copyright protection is not available. Authorization to photocopy items bearing individual AMS copyright notices at the bottom of their first page is granted by the AMS for libraries and other users registered with the Copyright Clearance Center (CCC) Transactional Reporting Service, provided the copies are for internal or personal use, or for the personal or internal use of the specific clients, and further provided the base of $\$ 4.25$ per copy $+\$ 0.25$ per page is paid directly to the CCC, 21 Congress St., Salem, MA 01970, and that the fee code for this journal is reported with the payment to CCC: $0003-0007 / 83 \$ 4.25+\$ 0.25$. Republication, systematic reproduction, and any other use of any material in this journal, unless exempted by the above statements, requires written permission or license from the AMS. 

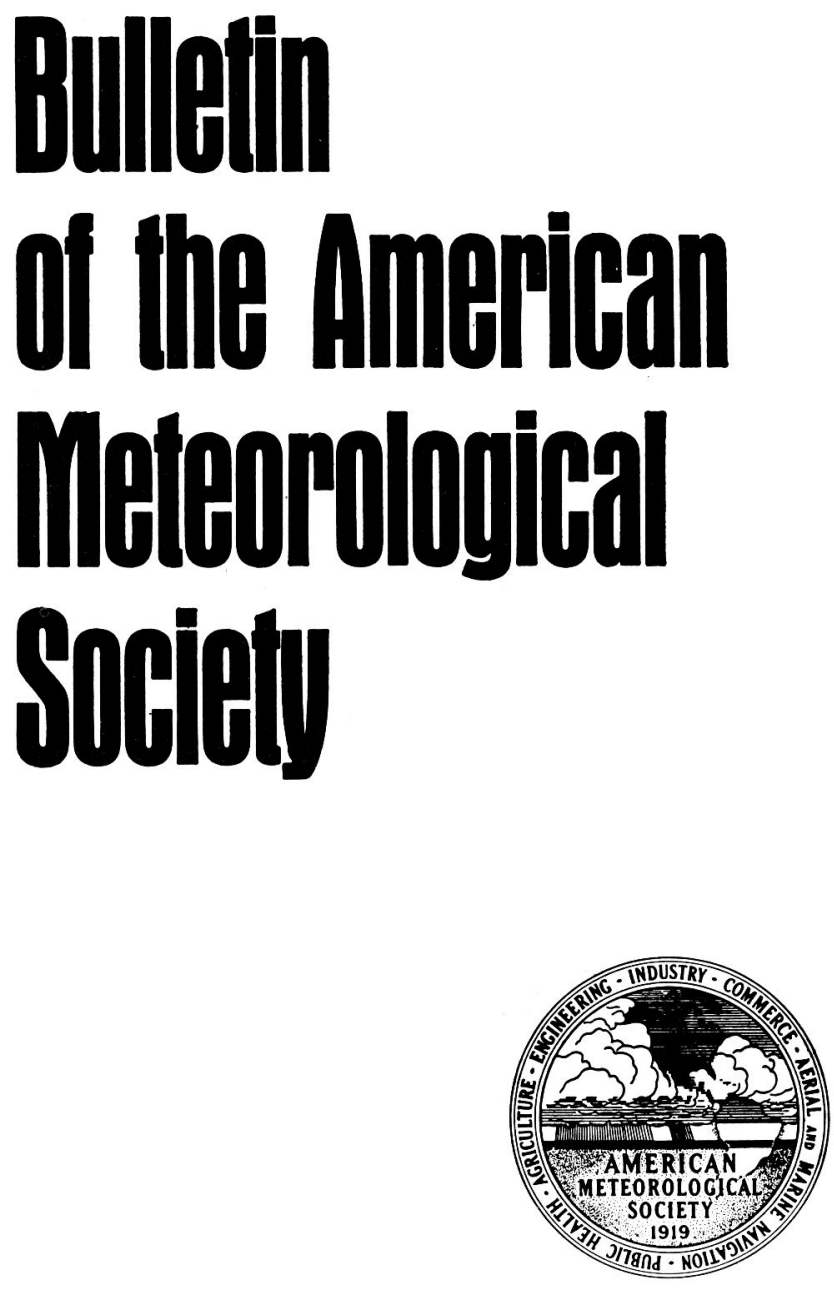

Volume 72

1991 


\section{AMS policy on using copyrighted materials}

Figures, tables and brief excerpts from the AMS primary Journals (BULLETIN OF THE AMS, JouRNAL OF THE atmospheric Sciences, Journal of Applied Meteorology, Journal of Physical Oceanography, Monthly Weather Review, Journal of Atmospheric and OCEanic Technology, Weather and Forecasting, Journal of Climate, and Meteorological Monographs) may be used in scientific educational works provided the original source is acknowledged. This policy also applies to earlier issues in which the copyright notice may have stated a different policy. Restrictions on other uses of material from the above-mentioned primary publications, including republication and copying of articles, are stated in the copyright notice near the front of each issue (see notice below for BULlETIN). It is emphasized that the policy stated in the opening sentence above applies only to primary publications listed there. For policy on copying and other uses of materials from Meteorological and Geoastrophysical abstracts, the Glossary of Meteorology, and all other AMS publications and books, please consult the copyright notice in each.

\footnotetext{
() Copyright 1991, American Meteorological Society (AMS). Permission to use figures, tables, and brief excerpts from this journal in scientific and educational work is hereby granted provided that the source is acknowledged. Any use of material in this journal that is determined to be "fair use" under Section 107 or that satisfies the conditions specified in Section 108 of the U.S. Copyright Law (17 USC, as revised by P.L. 94 553) does not require the Society's permission. Items that do not bear their own separate copyright notices either are in the public domain or are U.S. Government works for which copyright protection is not available. Authorization to photocopy items bearing individual AMS copyright notices at the bottom of their first page is granted by AMS for libraries and other users registered with the Copyright Clearance Center (CCC) Transactional Reporting Service, provided that the copies are for internal or personal use, or for the internal or personal use of specific clients, and further provided that the base of $\$ 4.25$ per copy plus $\$ 0.25$ per page is paid directly to CCC, 21 Congress St.. Salem, MA 01970, and that the following fee code for this journal is reported with the payment to CCC: $0003-0007 / 83 \$ 4.25+.25$. Republication, systematic reproduction, and other uses of any material in this journal, unless exempted by the above statements, require written permission or license from the AMS.
} 